\title{
Atomic Layer Deposition of Nanoalloys of Noble and Non-noble metals
}

Ranjith K. Ramachandran, ${ }^{a}$ Jolien Dendooven, ${ }^{\mathrm{a}}$ Matthias Filez, ${ }^{\mathrm{b} \#}$ Vladimir Galvita, ${ }^{\mathrm{b}}$ Hilde Poelman, ${ }^{\mathrm{b}}$ Eduardo Solano, ${ }^{\mathrm{a} \# \#}$ Matthias M. Minjauw, ${ }^{\mathrm{a}}$

Guy B. Marin ${ }^{\mathrm{b}}$ and Christophe Detavernier ${ }^{\mathrm{a}}$

aDepartment of Solid State Sciences, COCOON, Ghent University, Krijgslaan 281/S1, B9000 Ghent, Belgium

bLaboratory for Chemical Technology, Ghent University, Technologiepark 914, B-9052 Zwijnaarde, Belgium

\# Current address: Inorganic Chemistry and Catalysis group, Debye Institute for Nanomaterials Science, Utrecht University, Universiteitsweg 99, 3584 CG Utrecht, The Netherlands

\#\# Current address: ALBA Synchrotron, BL11-NCD, Carrer de la Llum 2-26, 08290 Cerdanyola del Vallès, Barcelona, Spain

\begin{abstract}
We present a novel ALD-based approach for the synthesis of bimetallic materials consisting of a noble metal along with a nonnoble metal such as Pt-M (M = In, Ga, Sn, etc.), with a precise control on the composition and size. First, a bilayer consisting of a metal oxide and a Pt film of the desired thickness is deposited on to the substrate. The film is then subjected to a temperature programmed reduction (TPR) under $\mathrm{H}_{2}$ atmosphere. In situ X-ray diffraction (XRD) measurements during TPR revealed the formation of $\mathrm{Pt}-\mathrm{M}$ bimetallic alloys with a phase determined by the $\mathrm{Pt} /(\mathrm{Pt}+\mathrm{M})$ atomic ratio of the as-deposited bilayer. Scanning electron microscopic (SEM) analysis revealed the formation nanoparticles after annealing, with the particle size controlled by the initial total thickness of the bilayer.
\end{abstract}

\section{Introduction}

In recent years, there has been an increasing interest in the use of atomic layer deposition (ALD) for the direct synthesis of bimetallic nanoparticles (BMNPs)(1-8). Using sequential self-limiting chemical reactions between gaseous precursor molecules and a solid surface, both core/shell $(4,7,8)$ and alloyed(1-3,5-7) nanoparticles have been fabricated with (sub-)monolayer precision. In these previous studies, typically two noble metal ALD processes were combined, either sequentially $(4,8)$ or in a supercycle approach $(1-3,5,6)$, and the nanoparticle morphology emerges as a result of the nucleation controlled growth of noble metals on oxide surfaces(9). To date, the deposition of Pd$\mathrm{Pt},(4,7,8) \mathrm{Ru}-\mathrm{Pt}(1,2,6)$ and $\operatorname{Ir}-\mathrm{Pt}(3)$ nanoparticles have been demonstrated.

Bimetallic materials consisting of a noble metal along with a non-noble metal, such as Pt-In, Pt-Ga and Pt-Sn, are actively explored in catalysis and gas sensing(10-14) and are usually synthesized by wet chemical methods.(10-15) The direct deposition of such bimetallic materials by ALD is challenging because of the lack of ALD chemistries for 
the deposition of the non-noble metals in their elemental state. Here, we report a general ALD-based two-step method for the controlled synthesis of Pt based bimetallic alloys containing non-noble metals such In, Sn, Ga etc.

Figure 1 depicts the basic principle of our approach for synthesizing different Pt-M bimetallic alloys $(16,17)$. Initially, a metal oxide $\left(\mathrm{MO}_{\mathrm{x}}\right)$ layer with a defined thickness is deposited on the plasma cleaned $\mathrm{SiO}_{2}$ substrate, which is then followed by the deposition of a controlled amount of Pt. The as-deposited $\mathrm{Pt} / \mathrm{MO}_{\mathrm{x}}$ bilayer is then subjected to a TPR up to $700{ }^{\circ} \mathrm{C}$ in $10 \% \mathrm{H}_{2} / \mathrm{N}_{2}$ environment at a heating rate of $0.2{ }^{\circ} \mathrm{C} / \mathrm{s}$, which results in the formation of alloyed $\mathrm{Pt}-\mathrm{M}$ particles. It is also demonstrated that the phase and size of the $\mathrm{Pt}-\mathrm{M}$ alloys can be controlled by changing the $\mathrm{MO}_{\mathrm{x}}$ thickness, the Pt thickness and/or the total deposited thickness.

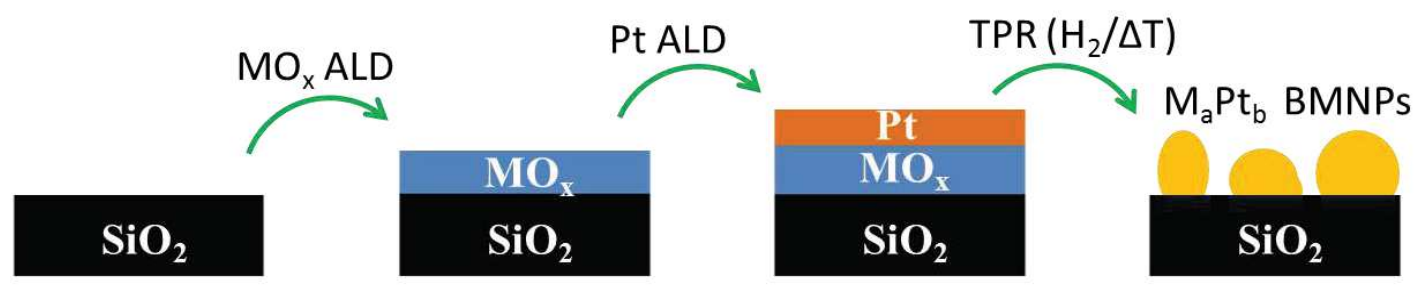

Figure 1. Schematic representation of the ALD based Pt-M BMNPs synthesis.

\section{Experimental}

All the depositions were performed in a home-built experimental cold-wall ALD chamber $(18,19)$ connected through a gate valve to a turbo pump backed up by a rotary pump. A second gate valve was installed for pre-evacuation of the chamber via a bypass line to the rotary pump. Pieces of silicon wafer covered with $100 \mathrm{~nm}$ thermally grown $\mathrm{SiO}_{2}$ were used as substrates, which were loaded into the vacuum chamber through a load-lock and were heated to $150{ }^{\circ} \mathrm{C}$ using a resistive heating plate. Prior to the deposition, the substrates were cleaned in situ using an $\mathrm{O}_{2}$ plasma exposure. Pt and $\mathrm{MO}_{\mathrm{x}}$ were deposited using the ALD processes reported elsewhere(20-24). For catalytic experiments, the mesoporous $\mathrm{SiO}_{2}$ powder, which was used as the support material, was loaded in a molybdenum sample cup and transferred into the ALD reactor through the load-lock and was placed on the heating plate. To ensure the saturation, extended exposure times were used for both precursor and reactants.

The thicknesses of the $\mathrm{Pt}$ and $\mathrm{MO}_{\mathrm{x}}$ films grown on the $\mathrm{SiO}_{2}$ substrate were determined by X-ray reflectivity (XRR) measurements using a Bruker D8 Discover system with $\mathrm{Cu} \mathrm{Ka}$ radiation. Alternatively, the deposited thicknesses were extracted from calibrated X-ray fluorescence (XRF) measurements. From the thickness, the specific weight of the Pt and $\mathrm{M}$ was calculated by assuming the densities of the films equal to that of bulk Pt and $\mathrm{MO}_{\mathrm{x}}$, respectively $(16,17)$. The XRF intensity counts and specific weight of materials were plotted against the thickness of the films (Figure 2), yielding a relationship that was used for determining the composition of the bilayer materials. 

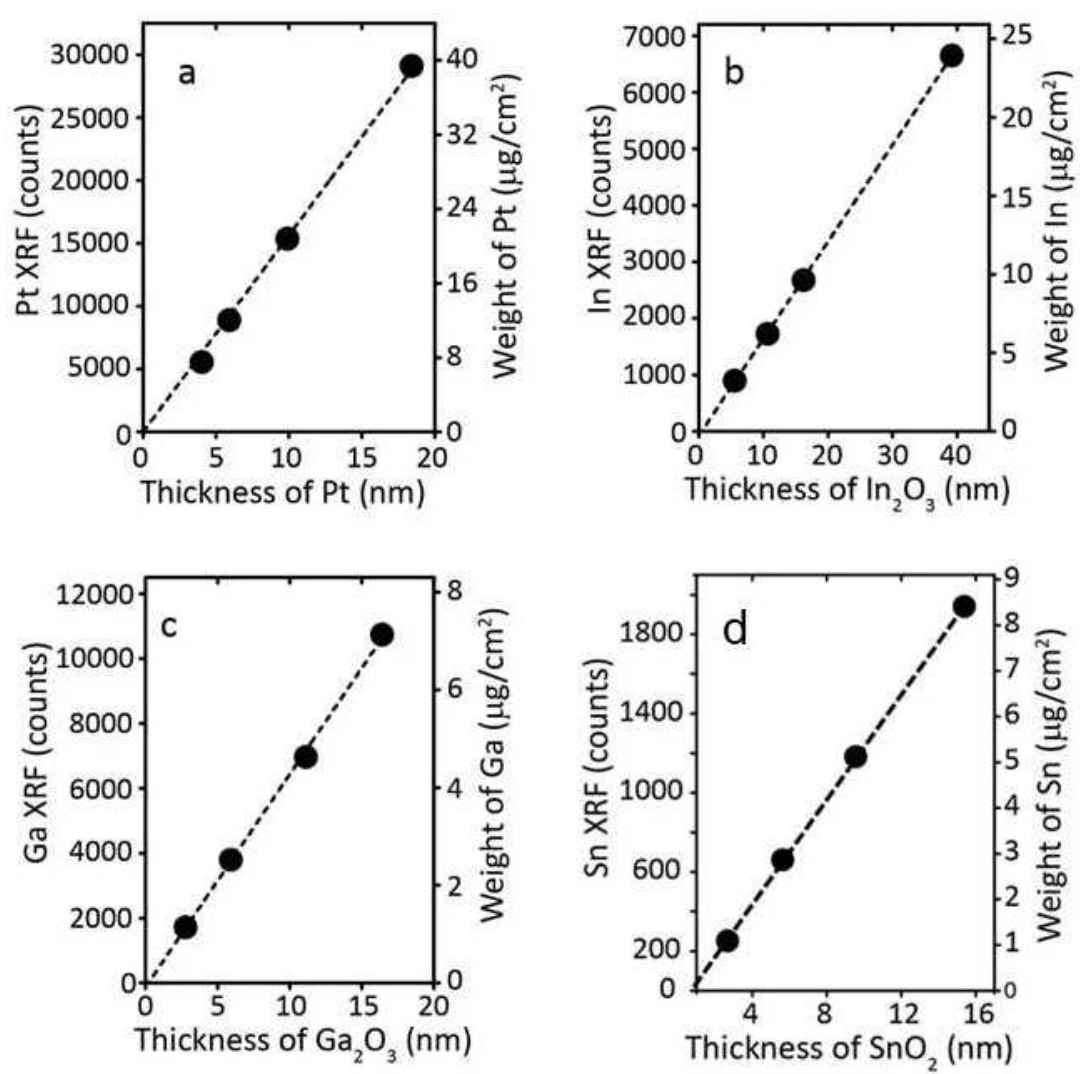

Figure 2. Variation of Pt (a), In (b), Ga (c) and Sn (d) XRF intensity (left y-axis) and weight (right axis) against the $\mathrm{Pt}, \mathrm{In}_{2} \mathrm{O}_{3}, \mathrm{Ga}_{2} \mathrm{O}_{3}$ and $\mathrm{SnO}_{2}$ film thickness, respectively.

The TPR treatment of the deposited bilayers in $10 \% \mathrm{H}_{2} / \mathrm{N}_{2}$ was performed in a homebuilt heating chamber mounted on a Bruker D8 diffractometer $(25,26)$ to enable in situ XRD characterization. A linear detector was used to collect the diffracted X-rays at $2 \mathrm{~s}$ time intervals.

Morphology of the bimetallic alloys formed after the annealing process was examined by scanning electron microscopy (SEM) measurements performed on a FEI Quanta 200F and a FEI Sirion instrument. Bright field (BF) scanning transmission electron microscopy (STEM BF) were performed using a JEOL JEM-2200FS, Cs-corrected microscope operated at $200 \mathrm{kV}$, which was equipped with a Schottky-type field-emission gun (FEG) and EDX JEOL JED-2300D. All samples were deposited by immersion onto a lacey carbon film on a copper support grid.

\section{Results and discussion}

\section{Phase tuning}

Pt-In system. Pt-In system was taken as a case study to demonstrate the phase tuning, which is achieved by controlling the ratio of the thickness of Pt to the thickness of $\operatorname{In}_{2} \mathrm{O}_{3}$ respectively(16). Three different samples were prepared with a constant Pt thickness of 6 $\mathrm{nm}$, while the $\mathrm{In}_{2} \mathrm{O}_{3}$ thickness was varied. With $\mathrm{In}_{2} \mathrm{O}_{3}$ thicknesses of $5.5 \mathrm{~nm}, 10.6 \mathrm{~nm}$ and 
$22 \mathrm{~nm}$ the as-deposited bilayers had a $\mathrm{Pt} /(\mathrm{Pt}+\mathrm{In})$ atomic ratio of $72 \%$ (sample $\mathrm{A}$ ), 58\% (sample B) and 38\% (sample C), respectively. Figure 3 (a), middle shows the timeresolved in situ XRD patterns recorded during $\mathrm{H}_{2} / \mathrm{N}_{2}$ TPR on sample A. Initially the pattern shows two diffraction peaks. A first peak at a $2 \theta$ angle of $30.6^{\circ}$ corresponds to $\mathrm{In}_{2} \mathrm{O}_{3}$ (222). The second peak at $40^{\circ}$ originates from metallic Pt. Recently, we reported that the crystallinity of $\operatorname{In}_{2} \mathrm{O}_{3}$ ALD films grown at lower temperatures $\left(100-150{ }^{\circ} \mathrm{C}\right)$ can be increased by a temperature treatment(21), which explain why the $\operatorname{In}_{2} \mathrm{O}_{3}$ (222) peak intensity is moderate initially and is intensified around $300{ }^{\circ} \mathrm{C}$. As the temperature increases further, a complete reduction of $\operatorname{In}_{2} \mathrm{O}_{3}$ to metallic In takes place at around $350{ }^{\circ} \mathrm{C}$, which is indicated by the disappearance of the XRD peak at $30.6^{\circ}$. Metallic In is liquid,(27) explaining the absence of diffraction peaks. At the same temperature of $350{ }^{\circ} \mathrm{C}$, a gradual shift of the Pt (111) peak towards a lower $2 \theta$ angle occurs. This is indicative of a progressive insertion of In in the Pt fcc structure. In incorporation causes the fcc lattice to expand which results in a concomitant decrease of the Pt (111) $2 \theta$ angle. The insertion of In into the Pt lattice facilitates the alloying between these two metals, and the stabilization of the diffraction peak at $39^{\circ}$ indicates the formation of an $\mathrm{InPt}_{3} \mathrm{fcc}$ structure. The $\mathrm{InPt}_{3}$ phase is also confirmed in the $20^{\circ}$ to $60^{\circ} 2 \theta$ scan that was measured after the TPR experiment [Figure 3 (a), right].

(a)

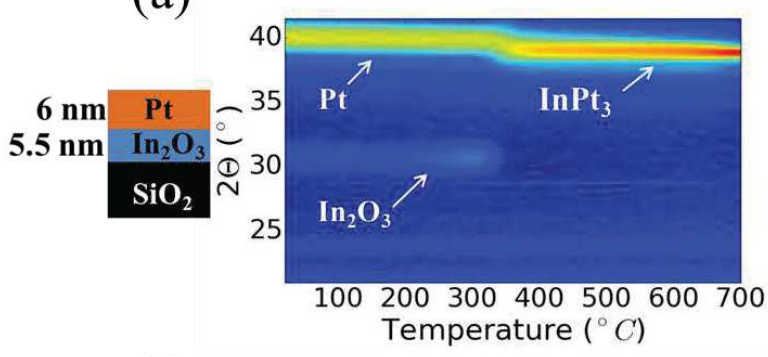

(b)

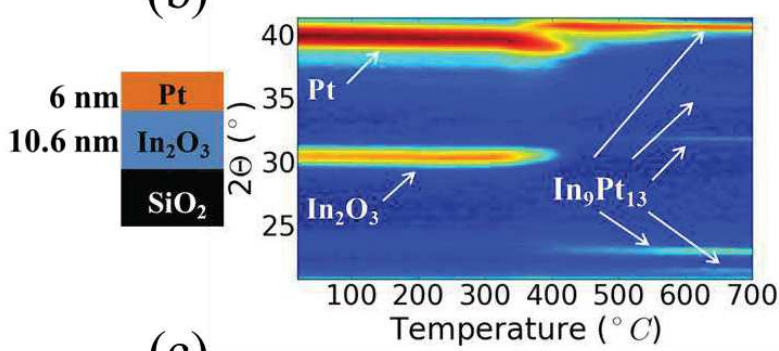

(c)

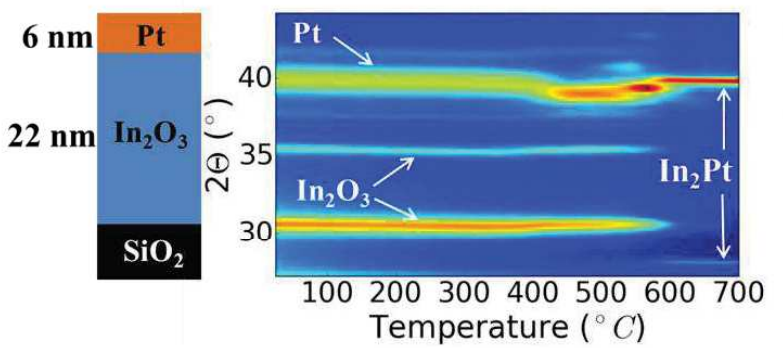

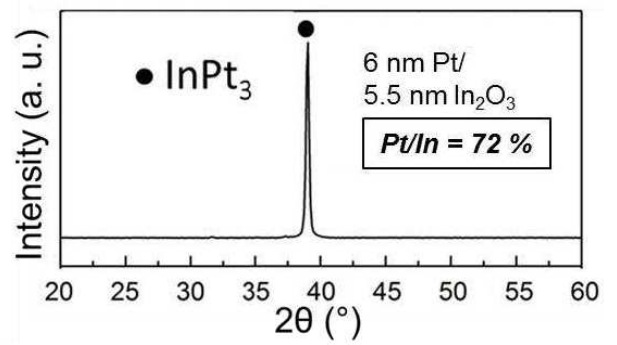
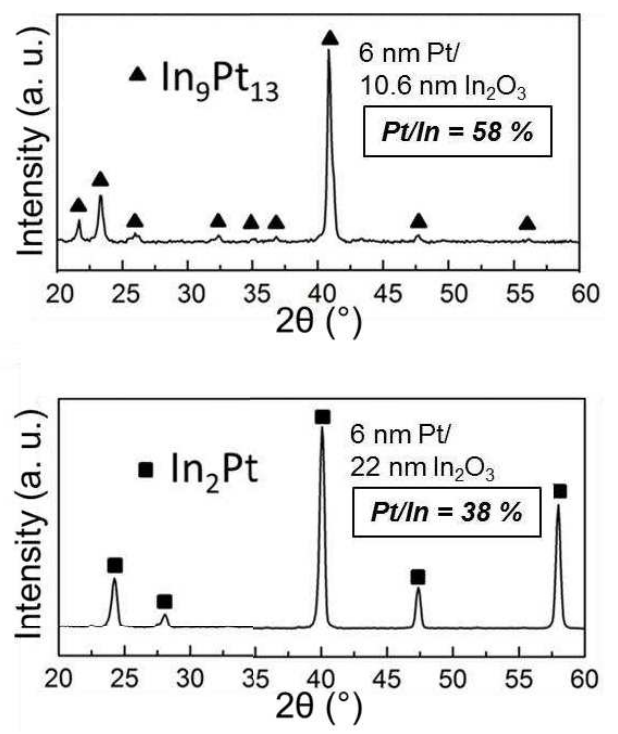

Figure 3. (Left) In situ XRD patterns during $\mathrm{H}_{2} / \mathrm{N}_{2}$ TPR of $\mathrm{Pt} / \mathrm{In}_{2} \mathrm{O}_{3}$ bilayer samples with a Pt/In atomic ratio of (a) $72 \%$ (sample A), (b) 58\% (sample B), and (c) $38 \%$ (sample C). Note the different $2 \theta$ range in (c). (Right) $20-60^{\circ} 2 \theta$ scans measured after the annealing experiment. 
The in situ XRD patterns recorded during $\mathrm{H}_{2} / \mathrm{N}_{2}$ TPR on samples $\mathrm{B}$ and $\mathrm{C}$ [Figure 3 (b) and (c)] behave initially more or less similar to that of sample A. Due to the higher $\mathrm{In}_{2} \mathrm{O}_{3}$ film thicknesses, the peak corresponding to $\operatorname{In}_{2} \mathrm{O}_{3}$ (222) is more intense and an additional peak at $35.5^{\circ}$, corresponding to $\mathrm{In}_{2} \mathrm{O}_{3}(400)$, is visible in the case of sample $\mathrm{C}$. Even below $\mathrm{In}_{2} \mathrm{O}_{3}$ reduction temperatures, In is gradually incorporated into the Pt lattice, which is indicated by the shift of Pt peak to a lower angle before the disappearance of the $\mathrm{In}_{2} \mathrm{O}_{3}$ peak. Once the whole $\operatorname{In}_{2} \mathrm{O}_{3}$ layer is reduced to metallic In, the high availability of metallic In is likely to further enrich and saturate the pre-existing Pt phase. This results in a phase transformation from $\mathrm{InPt}_{3}$ alloys into more In-rich $\mathrm{In}_{9} \mathrm{Pt}_{13}$ and $\mathrm{In}_{2} \mathrm{Pt}$ intermetallic compounds, respectively.

In summary, by varying the $\mathrm{In}_{2} \mathrm{O}_{3}$ layer thickness and thus changing the $\mathrm{Pt} / \mathrm{In}$ atomic ratio, the phase of the $\mathrm{In}_{\mathrm{a}} \mathrm{Pt}$ alloy that is formed upon TPR in $\mathrm{H}_{2} / \mathrm{N}_{2}$ can be controlled. Moreover, comparison of our results with the In-Pt phase diagram confirms that the obtained phases are in agreement with the predicted phases for the considered $\mathrm{Pt} /(\mathrm{Pt}+\mathrm{In})$ atomic ratios $(27,28)$. These experiments show that, in spite of the complex nature of the In-Pt phase diagram, our approach enables a high level of composition and phase control.

Pt-Ga and Pt-Sn systems. To illustrate the generality of the presented method, phase tuning of two more systems $(16,17)$, Pt-Ga and Pt-Sn, was demonstrated. Series of $\mathrm{Pt} / \mathrm{Ga}_{2} \mathrm{O}_{3}$ and $\mathrm{Pt} / \mathrm{SnO}_{2}$ bilayer samples with different $\mathrm{Pt} /(\mathrm{Pt}+\mathrm{Ga})$ and $\mathrm{Pt} /(\mathrm{Pt}+\mathrm{Sn})$ atomic ratios were prepared by using the respective ALD processes $(20,22,23)$. These bilayers were then subjected to a temperature programmed reduction (TPR) to $700{ }^{\circ} \mathrm{C}$ in $10 \%$ $\mathrm{H}_{2} / \mathrm{N}_{2}$ at a heating rate of $0.2{ }^{\circ} \mathrm{C} / \mathrm{s}$. Figure 4 (a) and (b) show the ex situ XRD measurements after TPR and cool down of the $\mathrm{Pt} / \mathrm{Ga}_{2} \mathrm{O}_{3}$ and $\mathrm{Pt} / \mathrm{SnO}_{2}$, respectively, which reveals the formation of different Pt-Ga and Pt-Sn alloys depending on the composition of the bilayers. For detailed information on this experiment, the reader is referred to the recent articles by R. K. Ramachandran et al.(16,17). These experiments show that, similar to Pt-In, the ALD of $\mathrm{Pt} / \mathrm{Ga}_{2} \mathrm{O}_{3}$ and $\mathrm{Pt} / \mathrm{SnO}_{2}$ bilayers followed by thermal reduction in hydrogen enables a high level of Pt-Ga and Pt-Sn phase control. 
(a)
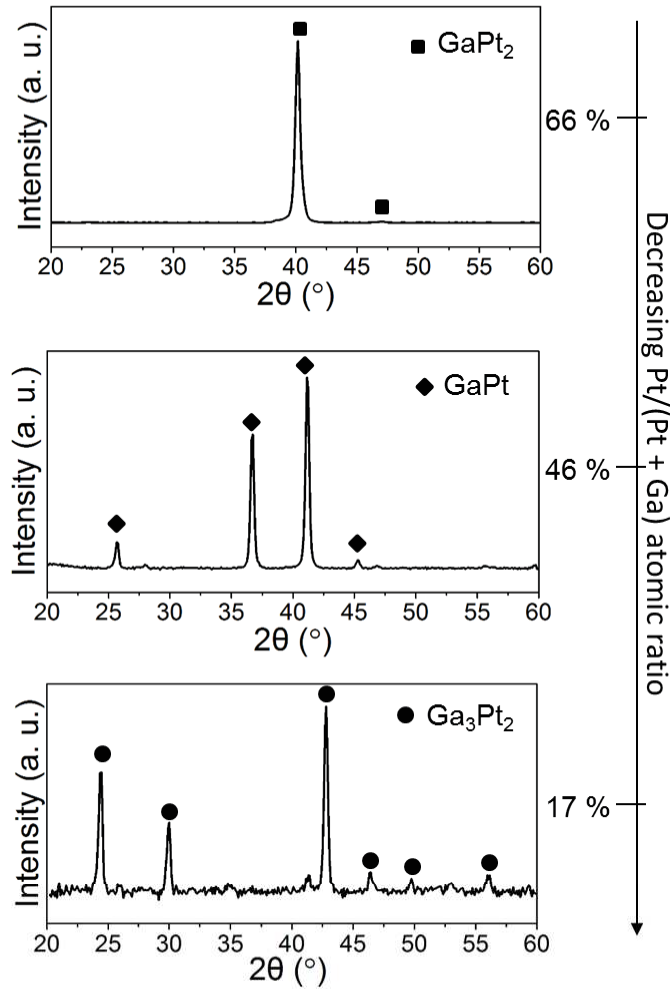

(b)

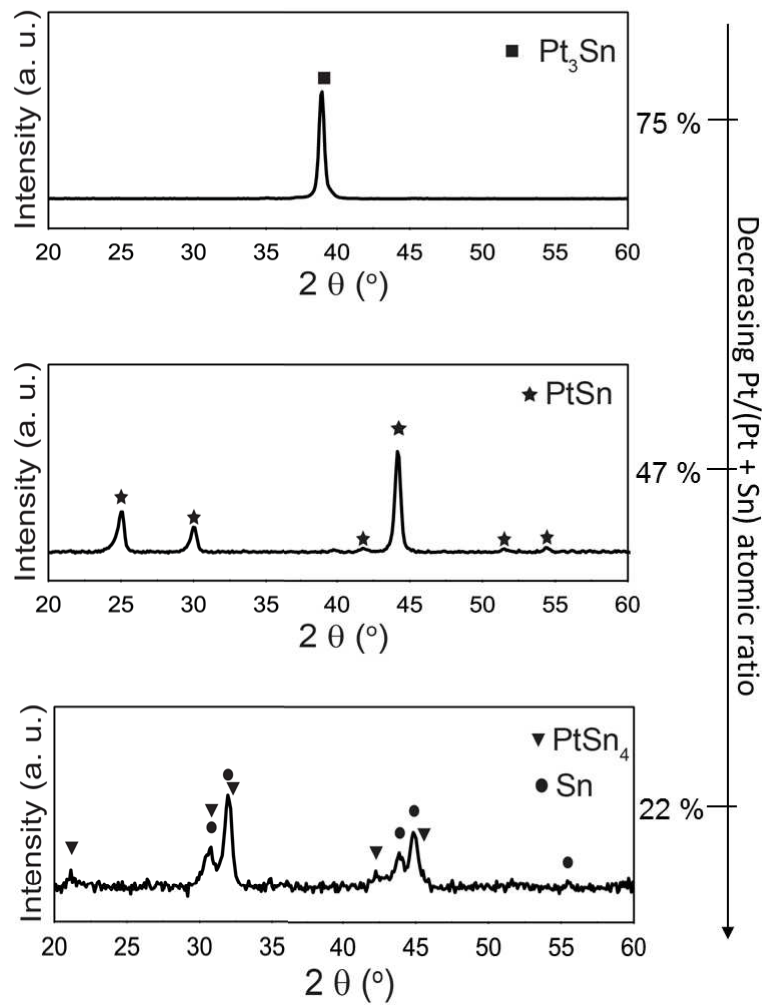

Figure 4. Ex situ XRD patterns measured after the TPR to $700{ }^{\circ} \mathrm{C}$ in $10 \% \mathrm{H}_{2} / \mathrm{N}_{2}$ of a) $\mathrm{Pt} / \mathrm{Ga}_{2} \mathrm{O}_{3}$ and $\mathrm{b}$ ) $\mathrm{Pt} / \mathrm{SnO}_{2}$ bilayer samples with different $\mathrm{Pt} /(\mathrm{Pt}+\mathrm{M})$ atomic ratios, where $\mathrm{M}$ $=\mathrm{Ga}$ and $\mathrm{Sn}$, respectively.

\section{$\underline{\text { Size tuning }}$}

In addition to phase control, the presented method enables tuning of the BMNP's size. Here, we demonstrate the precise control over the particle size of Pt-In BMNPs while keeping the composition of the alloy constant, which is achieved by controlling the total deposited thickness of the $\mathrm{Pt} / \mathrm{In}_{2} \mathrm{O}_{3}$ bilayer. To demonstrate this, films with a fixed $\mathrm{Pt} / \mathrm{In}$ atomic ratio of $38 \%$ but with a different total thickness were deposited: (a) $27.8 \mathrm{~nm}$ (5.8 $\left.\mathrm{nm} \mathrm{Pt}+22.0 \mathrm{~nm} \mathrm{In} \mathrm{I}_{3}\right)$, (b) $10.4 \mathrm{~nm}\left(2.1 \mathrm{~nm} \mathrm{Pt}+8.3 \mathrm{~nm} \mathrm{In}_{2} \mathrm{O}_{3}\right)$, (c) $2.46 \mathrm{~nm}(0.61 \mathrm{~nm} \mathrm{Pt}$ $\left.+1.85 \mathrm{~nm} \mathrm{In} \mathrm{I}_{3}\right)$ and (d) $1.33 \mathrm{~nm}\left(0.33 \mathrm{~nm} \mathrm{Pt}+1.0 \mathrm{~nm} \mathrm{In}_{2} \mathrm{O}_{3}\right)$. SEM characterization of the as-deposited samples showed relatively smooth surfaces. TPR of the samples a, b and $\mathrm{c}$ in $\mathrm{H}_{2} / \mathrm{N}_{2}$ to $700{ }^{\circ} \mathrm{C}$ resulted in the formation of the expected $\mathrm{In}_{2} \mathrm{Pt}$ phase, as confirmed by XRD (Figure 5). The sample d was too thin to be detected by XRD. The SEM images in Figure 6 confirm the formation of particles upon reduction in $\mathrm{H}_{2} / \mathrm{N}_{2}$. With decreasing total thickness of the deposited bilayer, the size of the particles decreased from micrometer range to $c a .4 \mathrm{~nm}$ particles. More detailed SEM analysis confirmed a particle size distribution of $2-7 \mathrm{~nm}$ for the sample $\mathrm{d}$ (total thickness $=1.33 \mathrm{~nm}$ ), which is promising towards applications such as catalysis. 

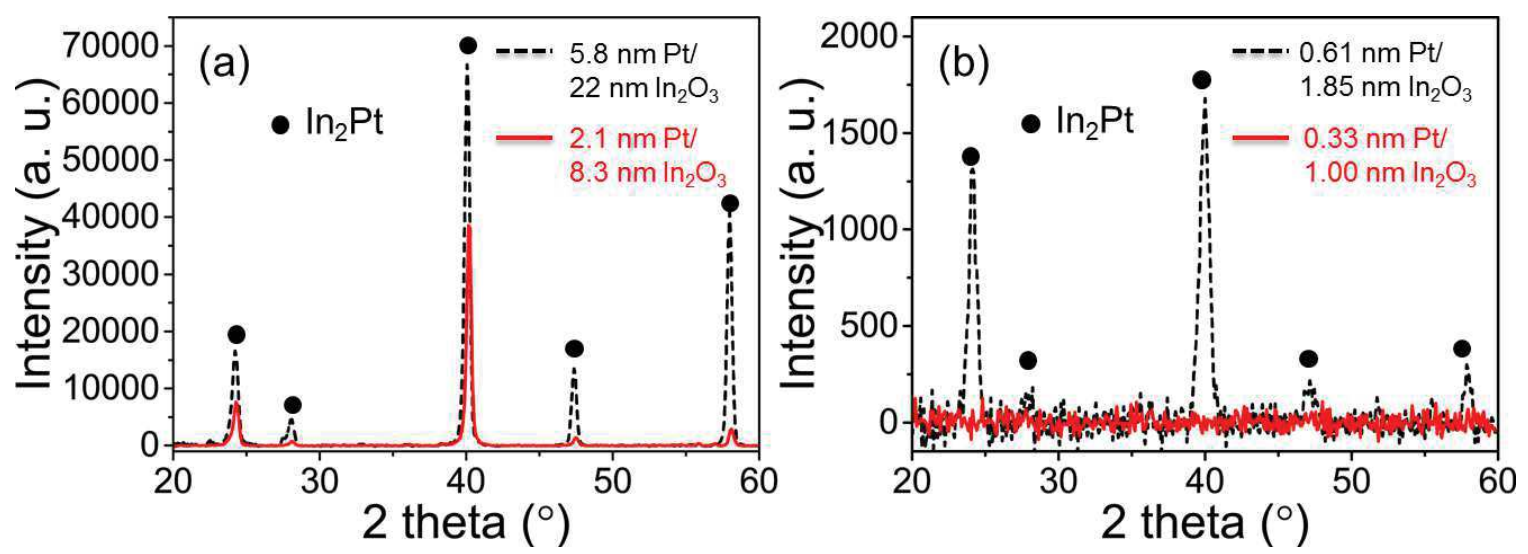

Figure 5. XRD patterns of annealed bilayered films with a Pt/(Pt+In) atomic ratio of ca. $38 \%$ and total thicknesses of (a) $27.8 \mathrm{~nm}$ (dashed) and 10.4 (solid) $\mathrm{nm}$ and (b) $2.46 \mathrm{~nm}$ (dashed) and $1.33 \mathrm{~nm}$ (solid).
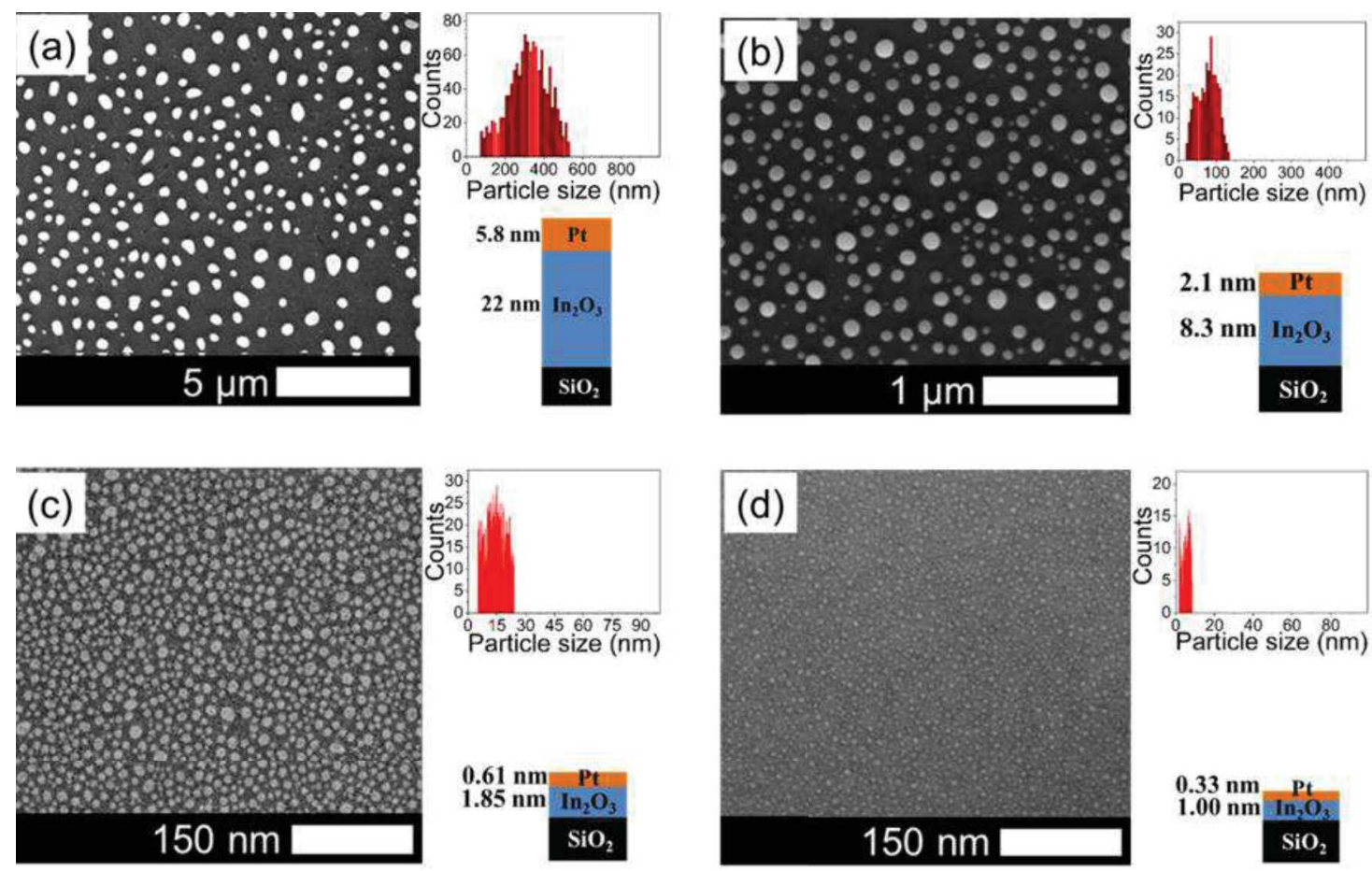

Figure 6. SEM images and particle size distribution curves of annealed bilayered films with a Pt/In atomic ratio of ca. $38 \%$ and total thicknesses of (a) $27.8 \mathrm{~nm}$, (b) $10.4 \mathrm{~nm}$, (c) $2.46 \mathrm{~nm}$ and (d) $1.33 \mathrm{~nm}$.

\section{$\underline{\text { Catalysis }}$}

Finally, in view of catalytic applications, the activity of a reduced $\mathrm{Pt}-\mathrm{In}$ loaded porous silica with $\mathrm{Pt} /(\mathrm{Pt}+\mathrm{In})$ atomic ratio of $75 \%$ is tested in the industrially important dehydrogenation of propane and compared to the activity of an ALD-prepared monometallic reference sample containing the same amount of $\mathrm{Pt}$, as determined by inductively coupled plasma mass spectrometry (ICP-MS). 
Catalytic activity measurements were performed at atmospheric pressure in a quartz micro reactor with an internal diameter of $10 \mathrm{~mm}$, which was placed inside an electric furnace. Typically, $120 \mathrm{mg}$ of catalyst was packed between quartz wool plugs. The temperature of the catalyst bed was measured with K-type thermocouples touching the outside and inside of the reactor at the position of the catalyst bed. The inlet gas flow rates were maintained by means of calibrated Brooks mass flow controllers. The feed and product gas streams were monitored online using a calibrated OmniStar Pfeiffer mass spectrometer (MS). MS signals were recorded for all major fragments of $\mathrm{C}_{3} \mathrm{H}_{8}, \mathrm{C}_{3} \mathrm{H}_{6}$, $\mathrm{C}_{2} \mathrm{H}_{6}, \mathrm{C}_{2} \mathrm{H}_{4}$, and $\mathrm{CH}_{4}$ species. Carbon balance with a maximum deviation of $15 \%$ was obtained.

The as-deposited samples were reduced in $1 \mathrm{ml} / \mathrm{s}$ flow of $5 \% \mathrm{H}_{2} / \mathrm{Ar}$ at $650{ }^{\circ} \mathrm{C}$ for $0.5 \mathrm{~h}$. The nanoparticle nature of the ALD-deposited material after TPR in hydrogen is evidenced by scanning transmission electron microscopy (STEM) in figure 7.

Then, an activity measurement was conducted for $10 \mathrm{~min}$ at $600{ }^{\circ} \mathrm{C}$. The site-time yield $\left(\mathrm{Y}, \mathrm{mols}^{-1} \cdot \mathrm{mol}_{\mathrm{Pt}, \mathrm{s}}{ }^{-1}\right)$ was calculated from the difference in the inlet and outlet molar flow rates, as measured relative to an internal standard (Ar) using an online quadrupole mass spectrometer, i.e.,

$$
\mathrm{Y}_{\mathrm{i}}=\left(\mathrm{F}_{0, \mathrm{i}}-\mathrm{F}_{\mathrm{i}}\right) / \mathrm{N}_{\mathrm{Pt}, \mathrm{s}}
$$

where $\mathrm{F}_{0, \mathrm{i}}$ and $\mathrm{F}_{\mathrm{i}}$, in $\mathrm{mol} \cdot \mathrm{s}^{-1}$, are the inlet and outlet molar flow rates of component $\mathrm{i}$, and $\mathrm{N}_{\mathrm{Pt}, \mathrm{s}}$, in molpt,s, is the amount of exposed (surface) Pt atoms in the sample. The latter was determined by $\mathrm{H}_{2}$ chemisorption using an AutoChem II 2920 (Micromeritics Instrument Corporation).
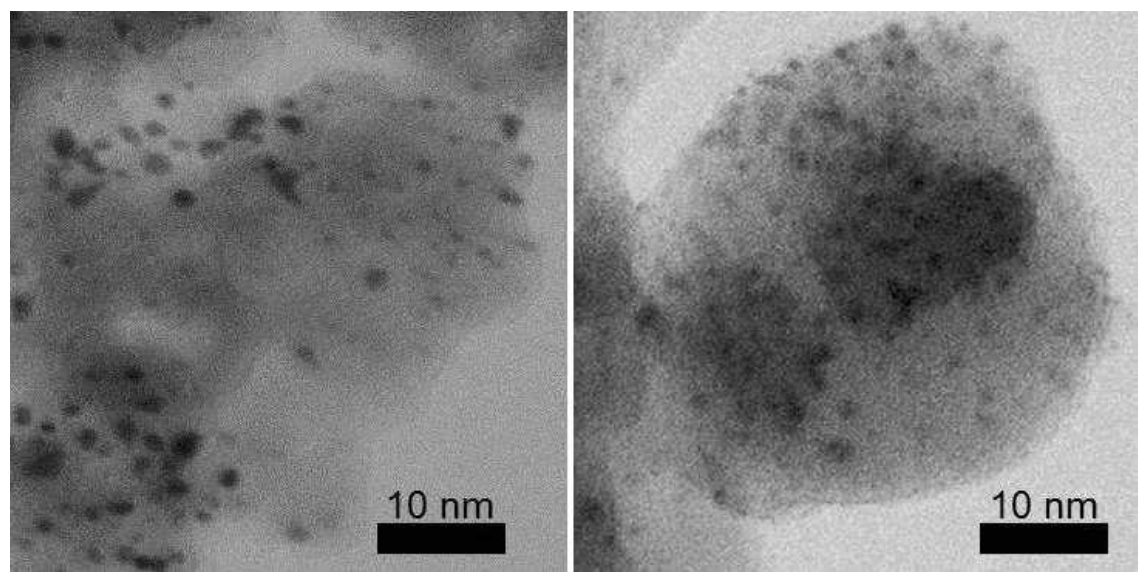

Figure 7. STEM bright field micrographs showing the overall morphology of the reduced catalysts, $\mathrm{Pt} / \mathrm{SiO}_{2}$ (left) $\mathrm{Pt}-\mathrm{In} / \mathrm{SiO}_{2}$ (right).

Figure 8 show the space time yield (Y) of propylene and hydrogen, which were the only detectable products, as a function of time-on-stream for both samples. The activity measurements clearly indicate that Pt-In bimetallic catalyst is more active, more selective and was less prone to coking than monometallic Pt catalyst. 


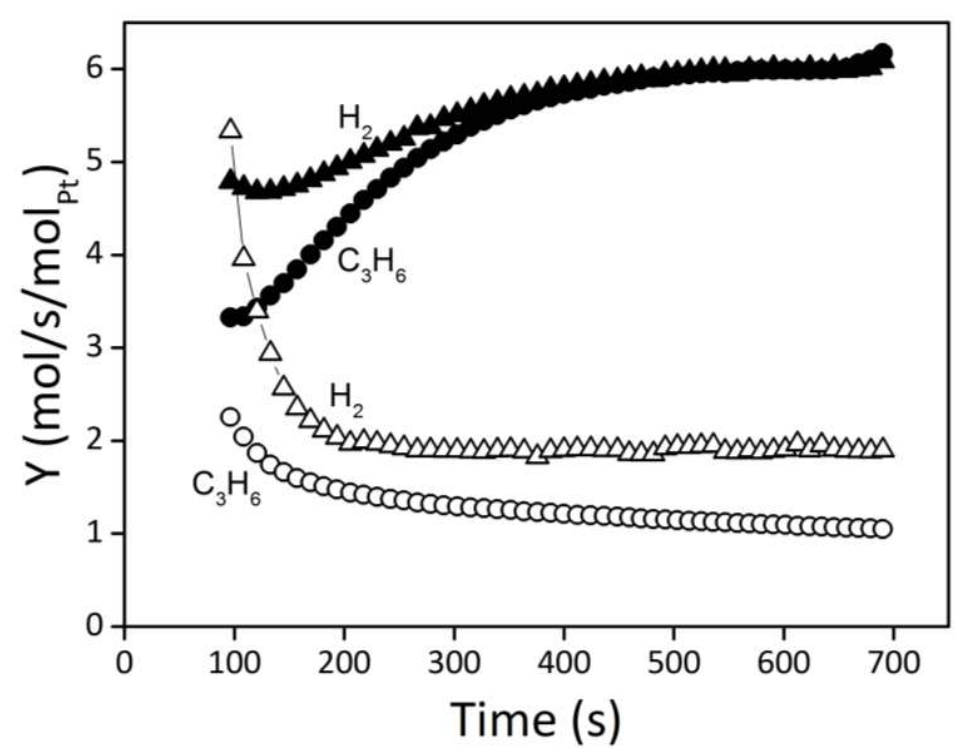

Figure 8. Catalytic propane dehydrogenation at $600{ }^{\circ} \mathrm{C}\left(W_{\text {cat }} / F_{\mathrm{C} 3 \mathrm{H} 8,0}=20 \mathrm{~kg}_{\mathrm{cat}} \cdot \mathrm{s} \cdot \mathrm{mol}^{-1}\right.$ and $P_{\mathrm{C} 3 \mathrm{H} 8,0}=20 \mathrm{kPa}$ at a total pressure of $101.3 \mathrm{kPa}$ ) using $\mathrm{Pt}-\mathrm{In} / \mathrm{SiO}_{2}$ (Solid symbol) and $\mathrm{Pt} / \mathrm{SiO}_{2}(\mathrm{Open}$ symbol) catalysts.

\section{Conclusion}

ALD processes have been successfully employed for the synthesis of bimetallic materials consisting of a noble metal along with a non-noble metal, with a precise control on the composition and size. First, thin films of $\mathrm{MO}_{\mathrm{x}}(\mathrm{M}=\mathrm{In}, \mathrm{Ga}$ or $\mathrm{Sn})$ and $\mathrm{Pt}$ were sequentially deposited using $\mathrm{ALD}$, yielding a $\mathrm{Pt} / \mathrm{MO}_{\mathrm{x}}$ nanocomposite. These bilayer structures were then subjected to a $\mathrm{H}_{2} / \mathrm{N}_{2}$ temperature programmed reduction (TPR) treatment, which resulted in the formation of alloyed Pt-M particles. The XRD measurements revealed the formation of different bimetallic alloys, which depends on the initial composition of the deposited films. It is shown that the composition and the size of the bimetallic alloys formed after TPR could be precisely controlled by changing the initial composition and thickness of the bilayers. Finally, the catalytic application of the bimetallic nanoparticles was demonstrated by propane dehydrogenation reactions, which revealed a better conversion for the $\mathrm{Pt} / \mathrm{In}$ bimetallic nanoparticles compared to the monometallic Pt.

\section{Acknowledgments}

This research was supported by the European Research Council (Starting Grant No. 239865), by the Flemish Research Foundation (FWO-Vlaanderen) (Project funding and research fellowships of J.D. and M.M.M.), the Flemish Government (Long-term structural funding-Methusalem funding), the Special Research Fund BOF of Ghent University (GOA 01G01513), and the IAP7/05 Interuniversity Attraction Poles Programme, Belgian State, Belgian Science Policy.

\section{References}

1. X. Jiang, T. M. Gür, F. B. Prinz, and S. F. Bent, Chem. Mater. 22, 3024 (2010).

2. S. T. Christensen, H. Feng, J. L. Libera, N. Guo, J. T. Miller, P. C. Stair, and J. W. Elam, Nano Lett. 10, 3047 (2010). 
3. S. T. Christensen and J. W. Elam, Chem. Mater. 22, 2517 (2010).

4. M. J. Weber, A. J. M. MacKus, M. a. Verheijen, C. Van Der Marel, and W. M. M. Kessels, Chem. Mater. 24, 2973 (2012).

5. J. Lu, K.-B. Low, Y. Lei, J. A. Libera, A. Nicholls, P. C. Stair, and J. W. Elam, Nat. Commun. 5, 3264 (2014).

6. A. C. Johansson, J. V. Larsen, M. a. Verheijen, K. B. Haugshøj, H. F. Clausen, W. M. M. Kessels, L. H. Christensen, and E. V. Thomsen, J. Catal. 311, 481 (2014).

7. K. Cao, Q. Zhu, B. Shan, and R. Chen, Sci. Rep. 5, 8470 (2015).

8. M. J. Weber, M. A. Verheijen, A. A. Bol, and W. M. M. Kessels, Nanotechnology 26, 94002 (2015).

9. C. T. Campbell, Surf. Sci. Rep. 27, 1 (1997).

10. F. Somodi, S. Werner, Z. Peng, A. Bean Getsoian, A. N. Mlinar, B. S. Yeo, and A. T. Bell, Langmuir 28, 3345 (2012).

11. X. Wang, L. Altmann, J. Stöver, V. Zielasek, M. Bäumer, K. Al-Shamery, H. Borchert, J. Parisi, and J. Kolny-Olesiak, Chem. Mater. 25, 1400 (2013).

12. G. Onyestyák, Catal. Commun. 38, 50 (2013).

13. H. Zhu, D. H. Anjum, Q. Wang, E. Abou-Hamad, L. Emsley, H. Dong, P. Laveille, L. Li, A. K. Samal, and J.-M. Basset, J. Catal. 320, 52 (2014).

14. E. A. Redekop, V. V Galvita, H. Poelman, V. Bliznuk, C. Detavernier, and G. B. Marin, ACS Catal. 4, 1812 (2014).

15. A. Virnovskaia, S. Jørgensen, J. Hafizovic, Ø. Prytz, E. Kleimenov, M. Hävecker, H. Bluhm, A. Knop-Gericke, R. Schlögl, and U. Olsbye, Surf. Sci. 601, 30 (2007).

16. R. K. Ramachandran, J. Dendooven, M. Filez, V. V. Galvita, H. Poelman, E. Solano, M. M. Minjauw, K. Devloo-Casier, E. Fonda, D. Hermida-Merino, W. Bras, G. B. Marin, and C. Detavernier, ACS Nano 10, 8770 (2016).

17. R. K. Ramachandran, M. Filez, J. Dendooven, V. V. Galvita, H. Poelman, E. Solano, E. Fonda, G. B. Marin, and C. Detavernier, RSC Adv. 7, 20201 (2017).

18. Q. Xie, Y.-L. Jiang, C. Detavernier, D. Deduytsche, R. L. Van Meirhaeghe, G.-P. Ru, B.-Z. Li, and X.-P. Qu, J. Appl. Phys. 102, 83521 (2007).

19. J. Musschoot, Q. Xie, D. Deduytsche, S. Van den Berghe, R. L. Van Meirhaeghe, and C. Detavernier, Microelectron. Eng. 86, 72 (2009).

20. M. N. Mullings, C. Hägglund, and S. F. Bent, J. Vac. Sci. Technol. A Vacuum, Surfaces, Film. 31, 61503 (2013).

21. R. K. Ramachandran, J. Dendooven, H. Poelman, and C. Detavernier, J. Phys. Chem. C 119, 11786 (2015).

22. R. K. Ramachandran, J. Dendooven, J. Botterman, S. Pulinthanathu Sree, D. Poelman, J. A. Martens, H. Poelman, and C. Detavernier, J. Mater. Chem. A 2, 19232 (2014).

23. J. Dendooven, R. K. Ramachandran, K. Devloo-Casier, G. Rampelberg, M. Filez, H. Poelman, G. B. Marin, E. Fonda, and C. Detavernier, J. Phys. Chem. C 117, 20557 (2013).

24. M. Filez, H. Poelman, R. K. Ramachandran, J. Dendooven, K. Devloo-Casier, E. Fonda, C. Detavernier, and G. B. Marin, Catal. Today 229, 2 (2014).

25. W. Knaepen, C. Detavernier, R. L. Van Meirhaeghe, J. Jordan Sweet, and C. Lavoie, Thin Solid Films 516, 4946 (2008).

26. W. Knaepen, S. Gaudet, C. Detavernier, R. L. Van Meirhaeghe, J. J. Sweet, and C. Lavoie, J. Appl. Phys. 105, 83532 (2009).

27. H. Okamoto, J. Phase Equilibria Diffus. 26, 399 (2005).

28. T. Biggs, S. S. Taylor, and E. Van Der Lingen, Platin. Met. Rev. 49, 2 (2005). 